\title{
Labyrinthe
}

2| 1999

Numéro 2

\section{Compte-rendu du séminaire franco-allemand (16-17 novembre 1998)}

sous la direction de Mme Zancarini-Fournel (Paris VIII) et de Mme Gilcher-Holthey (Bielefeld)

Kristina Schulz

\section{(2) OpenEdition}

Journals

Electronic version

URL: http://journals.openedition.org/labyrinthe/368

DOI: $10.4000 /$ labyrinthe.368

ISSN: 1950-6031

Publisher

Hermann

Printed version

Date of publication: 15 January 1999

Number of pages: 110-113

Electronic reference

Kristina Schulz, «Compte-rendu du séminaire franco-allemand (16-17 novembre 1998) », Labyrinthe

[Online], 2 | 1999, Online since 04 March 2005, connection on 03 May 2019. URL : http://

journals.openedition.org/labyrinthe/368; DOI : 10.4000/labyrinthe.368

This text was automatically generated on 3 May 2019.

Propriété intellectuelle 


\section{Compte-rendu du séminaire franco- allemand (16-17 novembre 1998)}

sous la direction de Mme Zancarini-Fournel (Paris VIII) et de Mme Gilcher-Holthey (Bielefeld)

Kristina Schulz 